\title{
Cadherins Associate with Distinct Stem Cell-Related Transcription Factors to Coordinate the Maintenance of Stemness in Triple-Negative Breast Cancer
}

\author{
Chuanwei Yang, ${ }^{1}$ Xuemei Zhao, ${ }^{2}$ Naipeng Cui, ${ }^{1,3}$ and Yulong Liang, \\ ${ }^{1}$ Breast Medical Oncology, The University of Texas MD Anderson Cancer Center, Houston, TX, USA \\ ${ }^{2}$ College of Pharmacy, Taishan Medical University, Tai'an, Shandong, China \\ ${ }^{3}$ Department of Breast Surgery, Affiliated Hospital of Hebei University, Baoding, Hebei, China \\ ${ }^{4}$ The Michael E. DeBakey Department of Surgery, Baylor College of Medicine, Houston, TX, USA
}

Correspondence should be addressed to Yulong Liang; yulong@bcm.edu

Received 2 November 2016; Revised 5 January 2017; Accepted 17 January 2017; Published 14 March 2017

Academic Editor: Tong-Chuan He

Copyright (C) 2017 Chuanwei Yang et al. This is an open access article distributed under the Creative Commons Attribution License, which permits unrestricted use, distribution, and reproduction in any medium, provided the original work is properly cited.

\begin{abstract}
Triple-negative breast cancer (TNBC) is an aggressive type of breast cancer with poor prognosis and is enriched in cancer stem cells (CSCs). However, it is not completely understood how the CSCs were maintained in TNBC. In this study, by analyzing The Cancer Genome Atlas (TCGA) provisional datasets and several small-size breast datasets, we found that cadherins (CDHs) 2, 4, 6 , and 17 were frequently amplified/overexpressed in $47 \%$ of TNBC while E-cadherin (CDH1) was downregulated/mutated at $10 \%$. The alterations of $\mathrm{CDH} 2 / 4 / 6 / 17$ were strongly associated with the elevated levels of several stem cell-related transcription factors (SC-TFs) including FOXM1, MCM2, WWTR1, SNAI1, and SOX9. CDH2/4/6/17-enriched genes including FOXM1 and MCM2 were also clustered and regulated by NFY (nuclear transcription factor Y) and/or EVI1/MECOM. Meanwhile, these SC-TFs including NFYA were upregulated in TNBC cells, but they were downregulated in luminal type of cells. Furthermore, small compounds might be predicted via the Connectivity Map analysis to target TNBC with the alterations of CDH2/4/6/17 and SC-TFs. Together with the important role of these SC-TFs in the stem cell regulation, our data provide novel insights into the maintenance of CSCs in TNBC and the discovery of these SC-TFs associated with the alterations of CDH2/4/6/17 has an implication in targeted therapy of TNBC.
\end{abstract}

\section{Introduction}

Breast cancer can be classified depending on the status of estrogen receptor (ER) and/or progesterone receptor (PGR) and epidermal growth factor receptor 2 (ERBB2/HER2) in clinic [1]. When all three markers ER, PGR and HER2 are negative in a tumor, it is called triple-negative breast cancer (TNBC). TNBC represents an aggressive type of breast cancer with poor prognosis [1]. The TNBC group is heterogeneous in nature, consisting of at least two major molecular subtypes including basal-like and claudin-low [2-4]. Both basal-like and claudin-low subtypes are enriched in cancer stem cells (CSCs) [4]. Although a lot of efforts have been made in this field, it is not fully understood how the stem cell population was enriched in TNBC.
Cadherins (CDHs) are a family of adhesion proteins consisting of more than 20 subtypes. These CDHs play important roles in cell-cell or cell-matrix junctions and regulate multiple aspects of fundamental cellular events such as cell polarity, motility, embryonic stem cell self-renewal and differentiation [5]. Among them, E-cadherin (CDH1) is a prototype and has been well characterized in stem cell maintenance and differentiation [6-8]. However, different subtypes of cadherins are expressed in distinct tissue types during development, and may involve in different aspect of cellular behavior. For instance, $\mathrm{CDH} 1$ is highly expressed in epithelial cells and modulate epithelial structure remodeling and the maintenance of epithelial stemness [6-8]. CDH2 (N-cadherin) is mostly expressed in the neuronal cells, and also involves in the process of epithelial-to-mesenchymal 
transition (EMT), which is correlated to the development of cancer stem cells (CSCs) [9-12]. Since CDH1 is critical for stem cell maintenance and regulation of epithelial cells, it raises a question whether other $\mathrm{CDHs}$ are involved in the maintenance of CSCs in breast cancer in addition to CDH1, especially under circumstances when CDH1 is deleted or lost, which remains relatively unexplored. In this study, we analyzed The Cancer Genome Atlas (TCGA) datasets containing over 1000 invasive breast cancer cases. We found that $\mathrm{CDH} 2,4,6$, and 17 were frequently amplified/overexpressed in breast cancer while CDH1 was downregulated/mutated. These changes affected the expression of several stem cellrelated transcription factors (SC-TFs) such as NFYA and WWTR1, etc. Moreover, based on CDH2/4/6/17-enriched gene profiling, several small compounds might be predicted via the Connectivity Map (CMap) analysis to target TNBC with the alterations of $\mathrm{CDH} 2 / 4 / 6 / 17$ and SC-TFs. Altogether, our findings of these SC-TFs associated with the alterations of $\mathrm{CDH} 2 / 4 / 6 / 17$ may have an implication in targeted therapy of TNBC.

\section{Materials and Methods}

2.1. Breast Cancer Samples and Cell Lines Datasets. Breast cancer sample data used in this study were in whole or part based upon data generated by the TCGA Research Network (http://cancergenome.nih.gov/), which include the complete tumors group $(n=960)$ and triple-negative group $(n=116)$ from the Breast Invasive Carcinoma (TCGA provisional, $n=1105$ ). TCGA datasets, as of December 15, 2016, contained the experimental data including gene mutations, copy number alterations (CNA), mRNA and protein expression and clinical data, and were retrieved from cBioPortal for Cancer Genomics (http://www.cbioportal.org/) [13]. Other breast cancer datasets used here including Gene Expression Omnibus (GEO) GSE3971 [14] and European Genome-phenome Archive (EGA) EGAS00000000083 [15] were accessed and retrieved from Oncomine (https://www .oncomine.org/). Breast cancer cell lines datasets (GEO GSE36139 and ArrayExpress E-MTAB-181) [16, 17] were retrieved from Cancer Cell Line Encyclopedia (CCLE) portal (http://www.broadinstitute.org/ccle) or UCSC Cancer Genomics Browser (http://xena.ucsc.edu/).

2.2. Data Analysis. Alterations of interested genes including amplifications, deletions, mutations, and up- or downregulation were retrieved from TCGA datasets with cBioPortal [13] or from other indicated datasets with Oncomine (https://www.oncomine.org/). Gene set enrichment analysis data (including mRNA level or RPPA [reverse phase protein assay]-based protein level) and survival data were also retrieved from cBioPortal with default parameters unless otherwise indicated. Gene Ontology (GO)/KEGG (Kyoto Encyclopedia of Genes and Genomes) or Reactome pathway analysis and transcription factor discovery were performed through the Database for Annotation, Visualization and Integrated Discovery (DAVID) Bioinformatics Resources 6.8 (https://david-d.ncifcrf.gov/). Heatmap was created from GenePattern according to the instructions (https://genepattern.broadinstitute.org/). Expression levels of stem cell-related transcription factors (SC-TFs) and several CDHs were retrieved from UCSC Cancer Browser with default parameters.

All $\mathrm{CDH}$ genes $(n=27)$ screened in this study include CDH1 (E-cadherin), CDH2 (N-cadherin), CDH3 (P-cadherin), CDH4 (R-cadherin), CDH5 (VE-cadherin), CDH6 (K-cadherin), CDH7 (cadherin 7), CDH8 (cadherin 8), CDH9 (T1-cadherin), CDH10 (T2-cadherin), CDH11 (OBcadherin), CDH12 (N-cadherin 2), CDH13 (H-cadherin), CDH15 (M-cadherin), CDH16 (KSP-cadherin), CDH17 (LIcadherin), CDH18 (cadherin 18), CDH20 (cadherin 20), PCDHGA12 (CDH21), CDH22 CDH23 CDH24 DCHS1 (CDH19, or CDH25), CDH26 DCHS2 (CDH27), CDHR3 (CDH28), and CDHR4 (CDH29).

SC-TFs used here include CTNNB1 ( $\beta$-catenin), FOXM1, FOXO3, GLI2, HIF1A, HMGA1B, KLF4, MAF (c-MAF), MCM2, NANOG, POU5F1 (Oct-3/4), PRDM14, SNAI1 (Snail), SOX2, SOX9, STAT3, WWTR1, TBX3, TWIST1, ZEB1, LIN28A, LIN28B, and MYC (c-Myc) [18-30].

2.3. Flow Cytometry. Stem cell population of triple-negative (or claudin-low) breast cancer cells MDA-MB231 and luminal cells SKBR3 was determined by flow cytometry with stem cell marker CD $24^{-/ \text {low }} \mathrm{CD} 44^{+/ \text {high }}$. Fluorochrome-conjugated monoclonal antibodies against CD24 (FITC, Cat\# 555478) and CD44 (PE, Cat\# 555428) were purchased from BD Biosciences (San Diego, CA, USA). Fluorescent staining of CD24 and CD44 was performed as described elsewhere [31]. The labeled cells were finally analyzed on a FACS LSRII (BD Biosciences). The experiments were independently repeated.

2.4. Connectivity Map (CMap). CDH2/4/6/17-enriched gene signature identified in this study, which included 101 genes with 12 downregulated and 89 upregulated, was used as a query for the CMap analysis according to the instructions (http://www.broadinstitute.org/cmap/) [32, 33]. CMap analyzes the association (i.e., the positive or negative correlation) between the given test signature and gene expression profiles of cell lines treated with specific concentrations of various drugs (perturbagens).

\section{Results}

3.1. CDH2/4/6/17 High/Amplified in Cooccurrence with CDH1 Low/Mutated Is Associated with TNBC. As previously known, CDH1 is highly expressed in ductal invasive breast cancer, but low or absent in lobular invasive breast cancer $[34,35]$. In terms of clinical classification based on ESR1/PGR or HER2 status, CDH1 expression is reduced in TNBC $[36,37]$. Then the question arises what are the status of other $\mathrm{CDH}$ in TNBC. Are they upregulated or downregulated or unchanged? Here, we wanted to determine whether the expression of other CDHs is altered in breast cancer, especially in TNBC since CDH1 is mostly downregulated or mutated in TNBC $[36,37]$. To investigate the status of CDHs in breast cancer, we screened 27 members 
of CDHs in TCGA datasets and found that CDH1 was indeed low expressed or mutated in $16 \%$ of TCGA samples, and other $\mathrm{CDHs}$ (especially $\mathrm{CDH} 17, \mathrm{CDH} 4, \mathrm{CDH} 26, \mathrm{CDH} 3 / 8$, and $\mathrm{CDH} 2 / 6 / 12$ ) were almost highly expressed or amplified (Supplementary Figure S1 in Supplementary Material at https://doi.org/10.1155/2017/5091541). In TNBC, CDH1, $\mathrm{CDH} 2, \mathrm{CDH} 4, \mathrm{CDH} 6, \mathrm{CDH} 17$, and $\mathrm{CDH} 26$ also exhibited marked alterations (Figure 1(a), Supplementary Figure S2). Since CDH26 (11\%) had a tendency to cooccur with CDH4 (15\%) (Figure 1(a)), we herein selected $\mathrm{CDH1} / 2 / 4 / 6 / 17$ for further study. As for CDH1, our data showed that it had positive correlations with ESR1 or HER2 (Supplementary Table S1), implying that $\mathrm{CDH} 1$ might be downregulated in TNBC (ESR1-/PGR- and HER2-). Actually, we found CDH1 was low expressed in TNBC than other breast cancers in a TCGA cohort (Figure 1(b)). However, CDH2/4/17 were remarkably altered in TNBC with high expression in most cases (Figure 1(b)). Also, we observed that CDH1 mRNA level was downregulated in most triple-negative cell lines from CCLE datasets (Figure 1(c)). Conversely, CDH2/4/6/17 (especially $\mathrm{CDH} 2,4$, and 6) mRNA levels were aberrantly upregulated in these triple-negative cell lines (Figure 1(c)). Furthermore, $\mathrm{CDH} 1$ low was associated with poor overall survival of TNBC patients (Figure 1(d)). Therefore, these findings indicated that $\mathrm{CDH} 2 / 4 / 6 / 17$ high combined with CDH1 low might be of importance in TNBC.

\subsection{Altered Expression of Stem Cell-Related Transcription Fac-} tors Is Concurrent with the Alterations of $\mathrm{CDH} 2 / 4 / 6 / 17$. Since $\mathrm{CDH} 1$ is vital for breast epithelial stem cell remodeling [5$7,38-40]$, we wanted to answer the question if $\mathrm{CDH} 2 / 4 / 6 / 17$ are involved in breast CSCs under the condition of loss of $\mathrm{CDH} 1$. One way that the alterations of $\mathrm{CDH} 2 / 4 / 6 / 17$ influence the behavior of CSCs is through the changes in stem cell-related transcription factors (SC-TFs). Here, we selected 23 SC-TFs (listed in the Methods section) and screened their associations with the alterations of $\mathrm{CDH} 2 / 4 / 6 / 17$ in TCGA datasets via cBioPortal. As shown in Table 1, there were 5 SC-TFs including MCM2, WWTR1, FOXM1, SNAI1, and SOX9, having a tendency to be cooccurrent with the alterations of 3-4 $\mathrm{CDH}$ s of $\mathrm{CDH} 2,4,6$, and 17. Meanwhile, RPPA data confirmed that 4 SC-TFs (FOXM1, WWTR1, SNAIl, and MYC) were highly expressed with the alterations of $\mathrm{CDH} 2 / 4 / 6 / 17$ (Table 2); 3 out of these 4 SC-TFs belonged to the aforementioned $5 \mathrm{SC}$-TFs. In contrast, the alteration events (mutations or deletions) of $\mathrm{CDH1}$ were mutually exclusive with high-level expressions of 9 out of 14 SC-TFs (Supplementary Tables S2), suggesting that CDH1 might be not a key protein for the alterations of SC-TFs. Taken together, these findings indicated that the alterations of SC-TFs were cooccurring with the alteration events of $\mathrm{CDH} 2 / 4 / 6 / 17$.

3.3. $\mathrm{CDH} 2 / 4 / 6 / 17-$ Associated Gene Enrichment Is Regulated by Stem Cell-Related Transcription Factors. We next established $\mathrm{CDH} 2 / 4 / 6 / 17$-enriched gene signature to analyze whether the enriched genes can be regulated by SC-TFs. This is a different way to show the relationship between the alterations of $\mathrm{CDH} / 4 / 6 / 17$ and SC-TFs. As shown in Figure 2(a), we first found that 199 genes were overlapped among CDH1and $\mathrm{CDH} 2$-enriched genes; after $\mathrm{CDH} 2-, \mathrm{CDH} 4-, \mathrm{CDH} 6-$, and $\mathrm{CDH} 17$-enriched genes were considered together, we generated a refined list of $\mathrm{CDH} 2 / 4 / 6 / 17$-associated genes (101 genes) (Figure 2(a), Supplementary Table S3), which were all contained in $\mathrm{CDH} 1 / 2$-enriched genes except 2 genes (KCNE4 and $\mathrm{ZDHHC1}$ ). $\mathrm{CDH} 2 / 4 / 6 / 17$-associated genes were mainly involved in mitotic cell cycle and DNA replication/repair (Figure 2(b)). Further analysis showed that these genes possibly participated into several signaling pathways including the MAPK-ERK pathway and the PI3K-mTOR pathway (data not shown). Among the $\mathrm{CDH} 2 / 4 / 6 / 17$-associated 101 genes, top 24 genes were strongly correlated with the alterations of $\mathrm{CDH} 2 / 4 / 6 / 17$ (Figure 2(c)). Also, 20 out of these 24 genes were highly altered in TNBC (Figure 2(d), compared to Supplementary Figure S3). Meanwhile, the aforementioned two transcription factors (MCM2 and FXOM1) were identified in this gene signature and highly expressed in the samples with the alterations of $\mathrm{CDH} 2 / 4 / 6 / 17$ (Supplementary Table S3).

To further examine the effect of $\mathrm{CDH} 2 / 4 / 6 / 17$ on CSCs, we performed transcription factor discovery analysis by using DAVID Bioinformatics Resources 6.8. Interestingly, $\mathrm{CDH} 2 / 4 / 6 / 17$-enriched genes including two SC-TFs (MCM2 and FOXM1) were mainly grouped into a cluster that can be regulated by Nuclear Transcription Factor Y (NFY) and/or MECOM (EVI1) (Table 3), both of which have been reported to be involved in stem cell regulation [41,42]. Therefore, our findings suggested that NFYs and MECOM might be the master transcription factors responsible for gene regulation and stem cell maintenance under the alterations of $\mathrm{CDH} 2 / 4 / 6 / 17$.

\subsection{CDH2/4/6/17-Enriched Stem Cell-Related Transcription} Factors Are Upregulated in TNBC. SC-TFs play important roles in the maintenance of breast cancer stem cells as a whole. To gain insights into the changes of SC-TFs in clinical subtypes, especially in TNBC, we first analyzed the correlation of SC-TFs with clinical markers (ESR1, PGR, and HER2). We found that two SC-TFs such as FOXM1, MYC exhibited modest negative correlation with ESR1/PGR or HER2 status (Supplementary Table S4). To further investigate the status of SC-TFs in TNBC, we analyzed the levels of CDH2/4/6/17associated SC-TFs in the samples and cell lines of TNBC. All 7 SC-TFs (i.e., FOXM1, WWTR1, NFYA, MCM2, SOX9, MECOM, and SNAII) were found to be amplified and/or upregulated in TCGA TNBC samples; the rates of their alterations were much higher than those in TCGA total breast samples (Figure 3(a) and Supplementary Figure S4). Next, we retrieved the levels of 6 out of 7 SC-TFs (since no available data for MECOM) in breast cancer cell lines [17] from UCSC cancer genomics browser. Most of 6 SC-TFs were consistently upregulated in TNBC cell lines including basal-like and claudin-low (Figure 3(b)). Conversely, these SC-TFs were downregulated in luminal subtype of breast cancer cells (Figure 3(b)). In parallel, the proportion of cancer stem cell population determined by $\mathrm{CD} 24^{-/ \text {low }} \mathrm{CD} 44^{+/ \text {high }}$ was simultaneously higher in TNBC cell lines than other subtypes of breast cancer cell lines (Table 4). For instance, in claudin-low (TNBC) MDA-MB231 cells, there were 69.6\% 


\begin{abstract}
$47 \%(55 / 116)$ in TCGA TNBC $(n=116)$ for the alterations of CDH2/4/6/17
CDH1 10\% H|

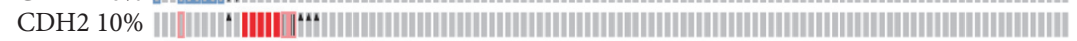

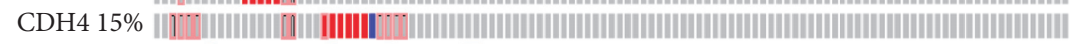

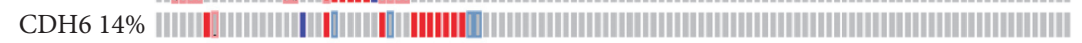

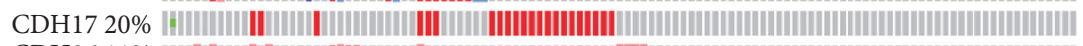

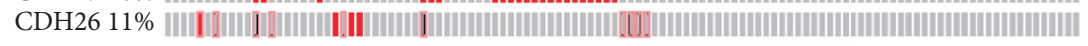

\begin{tabular}{|c|c|c|c|c|}
\hline \multicolumn{3}{|c|}{$\begin{array}{l}\text { Amplification } \\
\text { I Deep deletion } \\
\text { mRNA upregulation } \\
\text { [ mRNA downregulation }\end{array}$} & $\begin{array}{l}\text { Protein upregulation } \\
\text { Protein downregulation } \\
\text { Truncating mutation } \\
\text { Missense mutation }\end{array}$ & $\begin{array}{l}\text { tion } \\
\text { fulation } \\
\text { ition } \\
\text { on }\end{array}$ \\
\hline Gene A & Gene B & $p$ value & Log odds ratio & Association \\
\hline $\mathrm{CDH} 4$ & $\mathrm{CDH} 17$ & 0.016 & $<-3$ & Mutually exclusive, significant \\
\hline $\mathrm{CDH} 4$ & $\mathrm{CDH} 26$ & 0.022 & 1.567 & Cooccurrence, significant \\
\hline
\end{tabular}

(a)

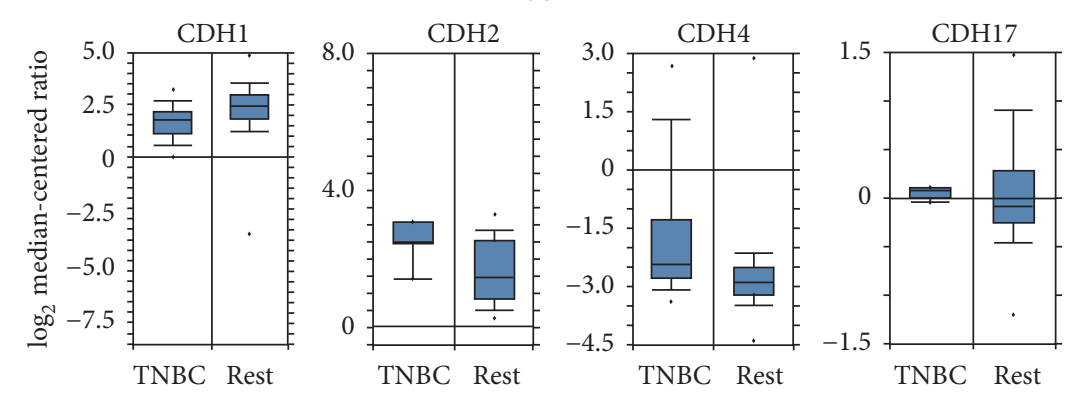

(b)

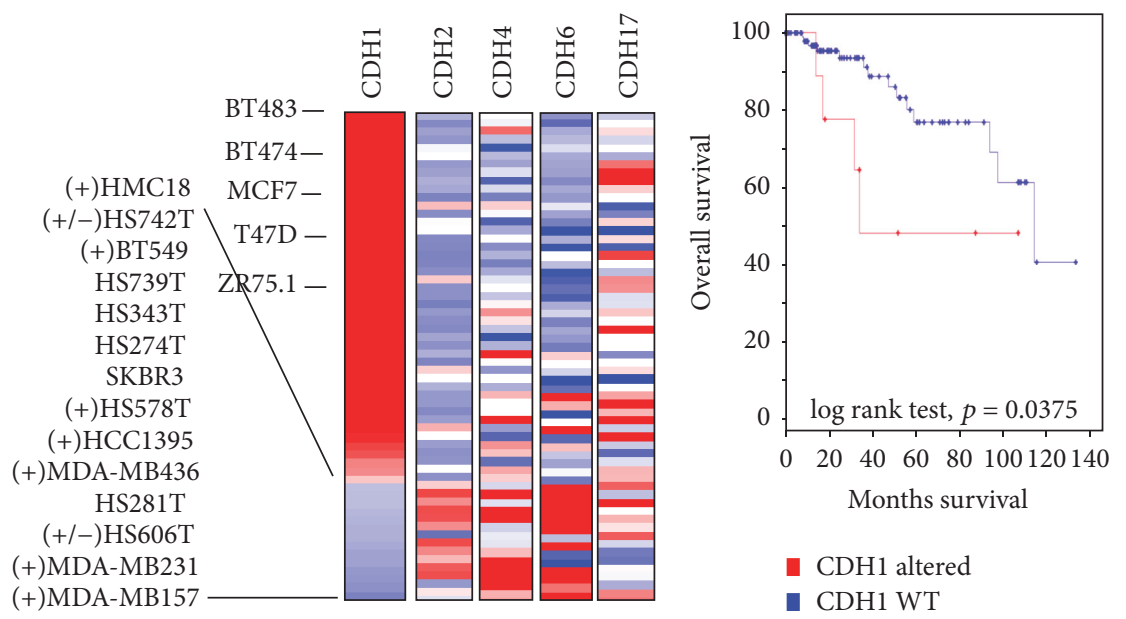

(c)

(d)

FIgURE 1: Alterations of CDHs in triple-negative breast cancer. (a) Alterations of CDH1, 2, 4, 6, 17, and 26 in TNBC samples from TCGA provisional datasets. The alterations here include deletion, amplification, downregulation, upregulation, and mutations. CDH1 was queried with EXP $<-2.0$ MUT HOMDEL PROT $<-2.0$ and other CDHs were queried with default parameters. Microarray data were used for mRNA expression level. The data were retrieved from cBioPortal as of December 15, 2016 (TNBC samples, $n=116$ ). CDH, cadherin; TNBC, triplenegative breast cancer; TCGA, The Cancer Genome Atlas. EXP, mRNA expression level; MUT, mutation; HOMDEL, homozygous deletion; PROT, protein level as determined by reverse phase protein assay (RPPA). (b) Expression of CDH1, 2, 4, and 17 in TNBC compared to nonTNBC samples. These data were retrieved as of December 15, 2016, from Oncomine. Rest indicates non-TNBC samples. For CDH1 (from partial TCGA dataset), TNBC, $n=46$; rest, $n=250$. For CDH2 (from Curtis breast dataset, European Genome-phenome Archive accession number EGAS00000000083), TNBC, $n=4$; rest, $n=17$. For CDH4 (from partial TCGA dataset), TNBC, $n=49$; rest, $n=300$. For CDH17 (from Zhao breast dataset, GEO accession number GSE3971), TNBC, $n=5$; rest, $n=37$. (c) Expression of CDH1, 2, 4, 6, and 17 in CCLE breast cancer cell lines. The expression data (mRNA level) of CDH1, 2, 4, 6, and 17 were retrieved from breast cancer cell lines dataset (GEO accession number GSE36139) by suing CCLE portal according to the instructions. Red represents upregulation; blue means downregulation. The symbol (+) represents triple-negative breast cancer cells, and (+/-) for TNBC-like cells. CCLE, Cancer Cell Line Encyclopedia. (d) Overall survival of TNBC patients with or without CDH1 alterations. TNBC samples $(n=116)$ were obtained from TCGA provisional dataset and retrieved with cBioPortal. For CDH1 altered: $n=10$ with median months survival $=33.97$; for CDH1 WT: $n=106$ with median months survival $=114.06$. 
TABLE 1: Cooccurrence of stem cell-related transcription factors in association with alterations of CDH2, 4, 6, and 17.

\begin{tabular}{|c|c|c|c|c|}
\hline Gene A (CDH) ${ }^{\mathrm{a}}$ & Gene B (SC-TF) ${ }^{\mathrm{b}}$ & $p$ value $^{c}$ & $\log$ odds ratio ${ }^{d}$ & Association $^{\mathrm{e}}$ \\
\hline \multirow{6}{*}{$\mathrm{CDH} 2$} & MCM2 & $<0.001$ & 1.340 & Tendency for cooccurrence, significant \\
\hline & WWTR1 & $<0.001$ & 1.235 & Tendency for cooccurrence, significant \\
\hline & FOXO3 & 0.003 & 1.080 & Tendency for cooccurrence, significant \\
\hline & FOXM1 & 0.019 & 0.763 & Tendency for cooccurrence, significant \\
\hline & SNAI1 & 0.022 & 0.864 & Tendency for cooccurrence, significant \\
\hline & SOX9 & 0.099 & 0.553 & Tendency for cooccurrence, marginal \\
\hline \multirow{10}{*}{$\mathrm{CDH} 4$} & FOXM1 & $<0.001$ & 1.256 & Tendency for cooccurrence, significant \\
\hline & MCM2 & $<0.001$ & 1.181 & Tendency for cooccurrence, significant \\
\hline & SNAI1 & $<0.001$ & 2.421 & Tendency for cooccurrence, significant \\
\hline & SOX9 & $<0.001$ & 1.088 & Tendency for cooccurrence, significant \\
\hline & NANOG & 0.004 & 1.281 & Tendency for cooccurrence, significant \\
\hline & POU5F1 & 0.004 & 0.949 & Tendency for cooccurrence, significant \\
\hline & HMGA1 & 0.005 & 0.854 & Tendency for cooccurrence, significant \\
\hline & MYC & 0.017 & 0.494 & Tendency for cooccurrence, significant \\
\hline & WWTR1 & 0.057 & 0.472 & Tendency for cooccurrence, marginal \\
\hline & HIF1A & 0.063 & 0.653 & Tendency for cooccurrence, marginal \\
\hline \multirow{9}{*}{$\mathrm{CDH} 6$} & GLI2 & $<0.001$ & 1.532 & Tendency for cooccurrence, significant \\
\hline & WWTR1 & $<0.001$ & 1.151 & Tendency for cooccurrence, significant \\
\hline & ZEB1 & $<0.001$ & 1.737 & Tendency for cooccurrence, significant \\
\hline & FOXM1 & 0.005 & 0.827 & Tendency for cooccurrence, significant \\
\hline & KLF4 & 0.028 & 1.093 & Tendency for cooccurrence, significant \\
\hline & SNAI1 & 0.039 & 0.710 & Tendency for cooccurrence, significant \\
\hline & POU5F1 & 0.043 & 0.768 & Tendency for cooccurrence, significant \\
\hline & NANOG & 0.062 & 0.968 & Tendency for cooccurrence, marginal \\
\hline & MCM2 & 0.071 & 0.593 & Tendency for cooccurrence, marginal \\
\hline \multirow{14}{*}{ CDH17 } & PRDM14 & $<0.001$ & 2.551 & Tendency for cooccurrence, significant \\
\hline & LIN28B & $<0.001$ & 1.122 & Tendency for cooccurrence, significant \\
\hline & MYC & $<0.001$ & $>3$ & Tendency for cooccurrence, significant \\
\hline & FOXM1 & 0.008 & 0.556 & Tendency for cooccurrence, significant \\
\hline & SNAI1 & 0.008 & 0.662 & Tendency for cooccurrence, significant \\
\hline & STAT3 & 0.009 & 0.692 & Tendency for cooccurrence, significant \\
\hline & SOX9 & 0.035 & 0.466 & Tendency for cooccurrence, significant \\
\hline & LIN28A & 0.040 & 0.842 & Tendency for cooccurrence, significant \\
\hline & KLF4 & 0.041 & -1.276 & Tendency towards mutual exclusivity, significant \\
\hline & GLI2 & 0.043 & -0.842 & Tendency towards mutual exclusivity, significant \\
\hline & MCM2 & 0.048 & 0.460 & Tendency for cooccurrence, significant \\
\hline & TBX3 & 0.069 & -0.693 & Tendency towards mutual exclusivity, marginal \\
\hline & FOXO3 & 0.073 & 0.418 & Tendency for cooccurrence, marginal \\
\hline & ZEB1 & 0.086 & -0.653 & Tendency towards mutual exclusivity, marginal \\
\hline
\end{tabular}

Note. ${ }^{\mathrm{a}} \mathrm{CDH}$, cadherin: here including $\mathrm{CDH} 2,4,6$, and 17 . ${ }^{\mathrm{b}} \mathrm{SC}-\mathrm{TF}$, stem cell-related transcription factor. SC-TFs in bold indicate that their occurrence simultaneously happened with the alterations of 3 or $4 \mathrm{CDHs}$ mentioned in a. ${ }^{c} p$ values are derived from Fisher's exact test; $p$ values less than 0.1 are included. ${ }^{d} \log$ odds ratio indicates the likelihood that the events in genes A and B are mutually exclusive or cooccurrent across the selected cases. The value quantifies how strongly the presence or absence of alterations in gene $\mathrm{A}$ is associated with the presence or absence of alterations in gene B in the selected cases. ${ }^{\mathrm{e}} \log$ odds ratio $>0$ : association towards cooccurrence; $\log$ odds ratio $\leq 0$ : association towards mutual exclusivity; significant means $p$ value $<0.05$; marginal means $p$ value is $0.05-0.1$.

TABLE 2: Cooccurrence of SC-TFs with CDH2, 4, 6, and 17 by RPPA analysis ${ }^{\mathrm{a}}$.

\begin{tabular}{lcccc}
\hline SC-TF & Locus & Expression change & $p$ value $^{\mathrm{b}}$ & $q$ value $^{\mathrm{c}}$ \\
\hline FOXM1 & $12 \mathrm{p} 13$ & Upregulation & $1.98 E-07$ & $6.69 E-06$ \\
SNAI1 & $20 \mathrm{q} 13.2$ & Upregulation & $2.15 E-04$ & $1.24 E-03$ \\
WWTR1 & $3 \mathrm{q} 23-\mathrm{q} 24$ & Upregulation & $3.86 E-03$ & 0.0136 \\
MYC & $8 \mathrm{q} 24.21$ & Upregulation & 0.0159 & 0.0417 \\
\hline
\end{tabular}

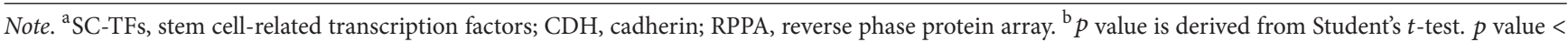
0.05 indicates significant. ${ }^{c} q$ value is derived from Benjamini-Hochberg procedure. $q$ value $<0.05$ indicates significant. 

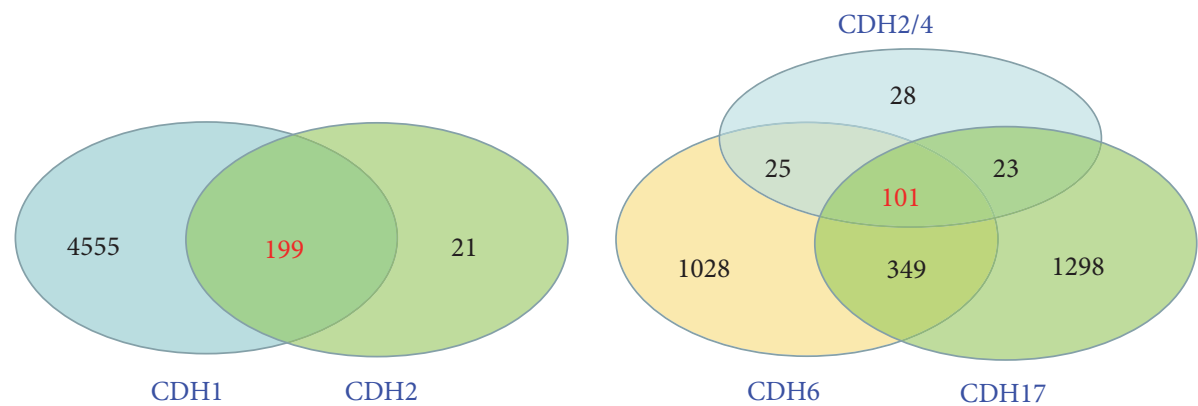

(a)

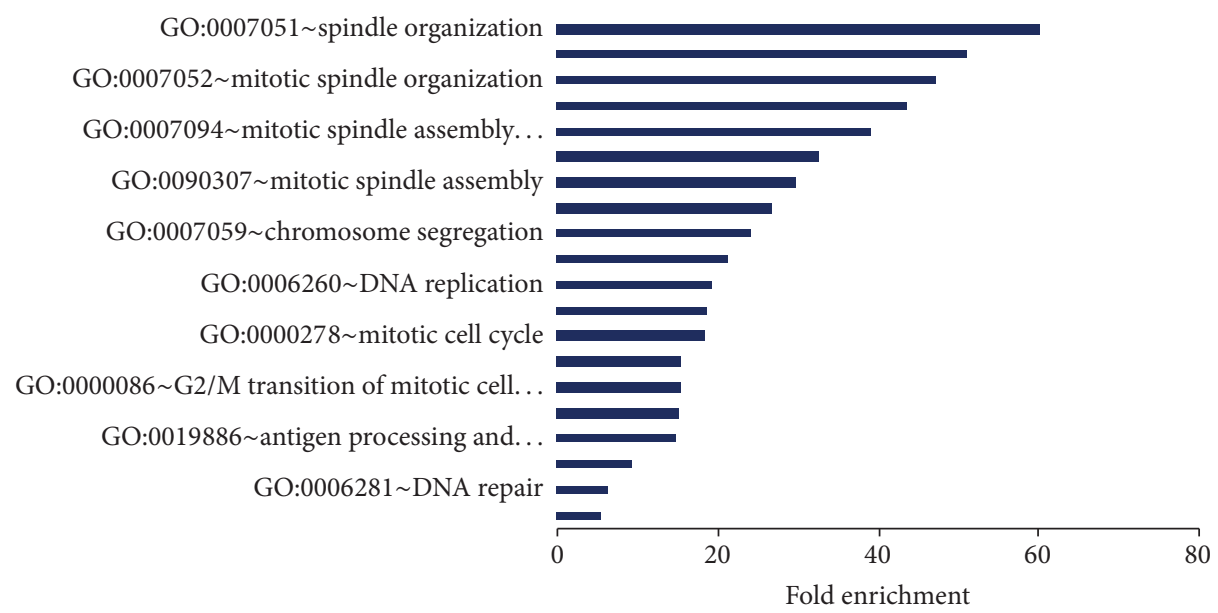

(b)

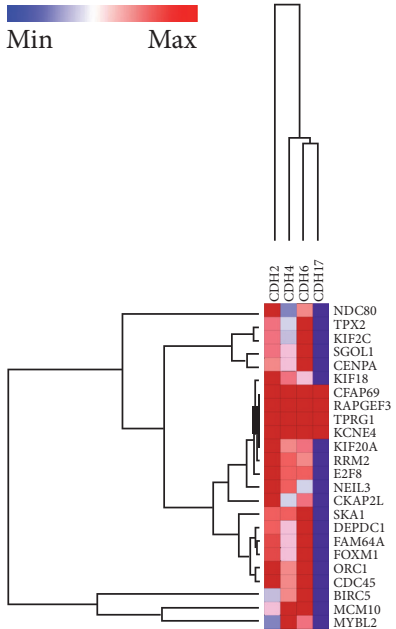

(c)

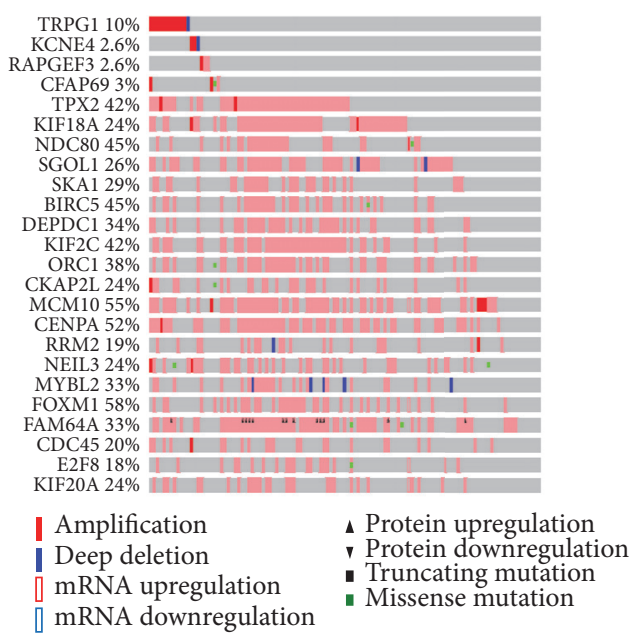

(d)

Figure 2: CDH2/4/6/17-enriched genes in breast cancer. (a) Venn diagrams showing the number of the overlaps between CDH1- and CDH2enriched genes (left panel) and the overlaps between $\mathrm{CDH} 2-, \mathrm{CDH} 4-, \mathrm{CDH} 6-$, and CDH17-enriched genes (right panel). The enriched genes for each individual altered cadherin were retrieved with cBioPortal enrichments module from TCGA provisional breast datasets (complete tumor group, $n=960$ ). CDH1 was queried with EXP $<-2.0$ MUT HOMDEL PROT $<-2.0$ and other CDHs were queried with default parameters. The genes were selected with $p<0.01$ (derived from Student $t$-test) and $q<0.01$ (derived from Benjamini-Hochberg procedure). EXP, mRNA expression level; MUT, mutation; HOMDEL, homozygous deletion; PROT, protein level as determined by reverse phase protein assay (RPPA). (b) Gene Ontology (GO) analysis of CDH2/4/6/17-enriched genes with DAVID Bioinformatics Resources 6.8. Fold enrichment indicates the magnitude of enrichment compared to population background regarding a given term. DAVID, Database for Annotation, Visualization, and Integrated Discovery. (c) Clustering analysis of top 24 out of $101 \mathrm{CDH} / 4 / 6 / 17$-enriched genes. Clustering analysis was performed in GenePattern according to the instructions. Min, minimal level; Max, maximal level. (d) Alterations of top 24 from $101 \mathrm{CDH} 2 / 4 / 6 / 17$-enriched genes in TNBC. TNBC samples $(n=116)$ were obtained from TCGA provisional dataset as of December 15, 2016. The data were retrieved from cBioPortal with default parameters for mutations, copy number alterations, mRNA levels, and protein levels. 


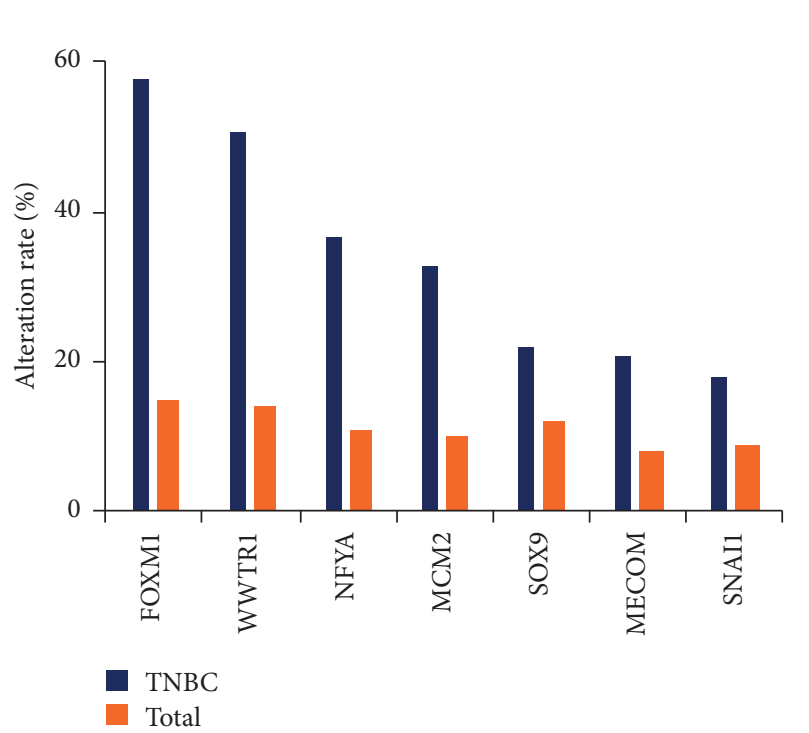

(a)

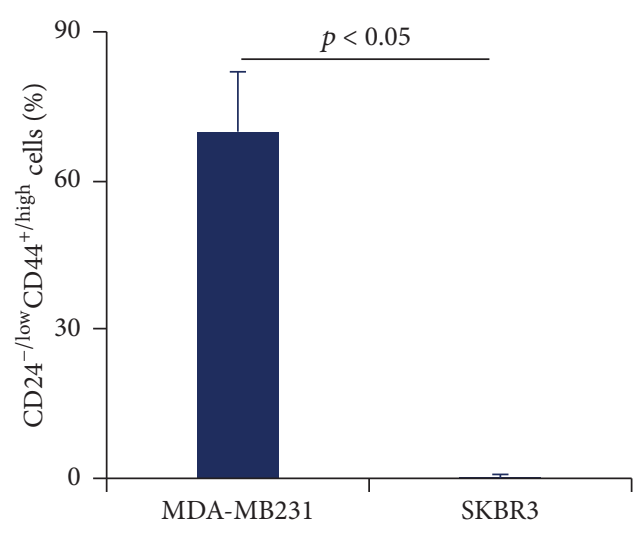

(c)

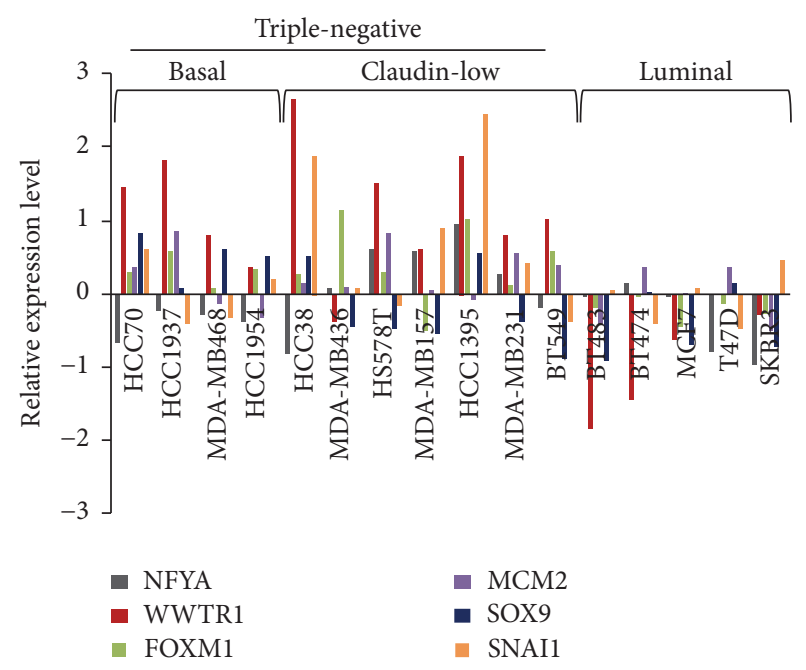

(b)

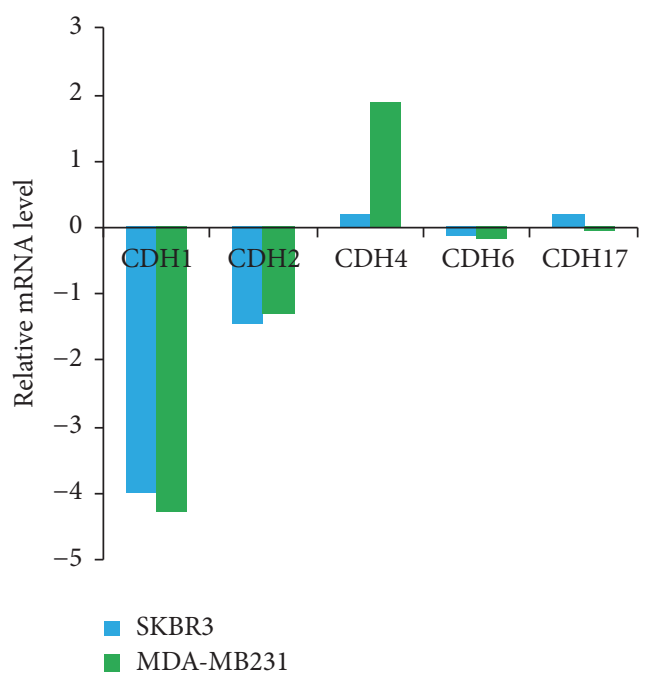

(d)

FIGURE 3: Stem cell-related transcription factors and cancer stem cells are enriched in TNBC cells. (a) The alteration rates of stem cell-related transcription factors (SC-TFs) in TCGA breast cancer samples $(n=960)$ or TCGA TNBC samples $(n=116)$. (b) The expression levels of SC-TFs were elevated in TNBC cells including basal-like and claudin-low. The expression data of the indicated SC-TFs were retrieved from breast cancer cell lines dataset (ArrayExpress accession number E-MTAB-181) by suing UCSC Cancer Genomic Browser according to the instructions. (c) The population of CSCs was higher in basal-like cells MDA-MB231 but lower in luminal subtype of cells SKBR3. The population of CSCs was determined by the staining of stem cell marker CD24-/low CD $44^{+/ \text {high }}$ followed by flow cytometry. (d) The expression levels of CDH1, 2, 4, 6, and 17 in TNBC claudin-low MDA-MB231 cells and luminal subtype of cells SKBR3. The expression data of CDH1, 2, 4,6 , and 17 in both cell lines were retrieved from the same dataset as described in (b).

of them exhibiting $\mathrm{CD} 24^{-/ \text {low }} \mathrm{CD} 44^{+/ \text {high }}$, which was dramatically higher than luminal SKBR3 cells $(0.21 \%)$ (Figure 3(c), Supplementary Figure S5). Furthermore, at least $\mathrm{CDH} 4$ (among CDH2/4/6/17) was expressed at a higher level in MDA-MB231 than in SKBR3, while CDH1 was low expressed in both MDA-MB231 and SKBR3 (Figure 3(d)), as reported previously [43-45]. Therefore, these findings strongly suggested that $\mathrm{CDH} 2 / 4 / 6 / 17-\mathrm{SC}-\mathrm{TFs}$ axis might play a key role in the enrichment of CSCs in TNBC.
3.5. TNBC Cells with the Alterations of CDH2/4/6/17-SC-TFs Axis May Be Targeted with the Perturbagens Discovered with the Connectivity Map. To evaluate whether TNBC cells with the alterations of CDH2/4/6/17-SC-TFs axis can be targeted, we adopted a web-based resource CMap. The CMap utilizes a pattern-matching algorithm to link the compounds (perturbagens) with physiological or pathological phenotypes by measuring similarities in gene expression, and therefore can be used to predict the affected pathways through the 
TABLE 3: Potential transcription factors predicted using DAVID analysis ${ }^{\mathrm{a}}$.

\begin{tabular}{|c|c|c|c|c|}
\hline \multirow{2}{*}{ Transcription factor ${ }^{\mathrm{b}}$} & \multirow{2}{*}{$\%^{c}$} & \multirow{2}{*}{ Fold enrichment $^{\mathrm{d}}$} & \multicolumn{2}{|c|}{ Statistics } \\
\hline & & & $p$ value $^{\mathrm{e}}$ & Benjamini $^{\mathrm{f}}$ \\
\hline NFY & 61.63 & 1.520018153 & $9.59 \mathrm{E}-05$ & 0.016736215 \\
\hline EVI1 & 86.05 & 1.216541909 & $8.52 E-04$ & $0.072283654^{*}$ \\
\hline $\mathrm{E} 2 \mathrm{~F}$ & 63.95 & 1.335510686 & 0.002616935 & 0.142494828 \\
\hline MEF2 & 75.58 & 1.192911873 & 0.013046475 & 0.438881091 \\
\hline MEIS1 & 50.00 & 1.305125299 & 0.023933933 & 0.573746109 \\
\hline COMP1 & 52.33 & 1.270475168 & 0.031160597 & 0.604888864 \\
\hline
\end{tabular}

Note. ${ }^{\mathrm{a}}$ DAVID, Database for Annotation, Visualization, and Integrated Discovery version $6.8 .{ }^{\mathrm{b}}$ Transcription factors in bold indicate significantly predicted transcription factors. EVIl, also called MECOM. ${ }^{c} \%$ means the percentage of genes regulated by the indicated transcription factor among the total query genes.

${ }^{\mathrm{d}}$ Fold enrichment indicates the magnitude of enrichment compared to population background regarding a given term. ${ }^{\mathrm{e}} p$ value is derived from modified Fisher's exact test (also called EASE score). ${ }^{\mathrm{f}}$ Benjamini indicates a more conservative method to control family-wide false discovery under certain rate. ${ }^{*}$ Marginal significance.

TABLE 4: Cancer stem cell population in different breast cancer cell lines ${ }^{\mathrm{a}}$.

\begin{tabular}{|c|c|c|c|}
\hline \multirow{2}{*}{ Breast cancer cell lines } & \multicolumn{3}{|c|}{ Stem cell markers ${ }^{\mathrm{b}}$} \\
\hline & $\mathrm{CD} 24^{-/ \text {low }} \mathrm{CD} 44^{+/ \text {high }}(\%)$ & ALDH1 activity & Side population \\
\hline \multicolumn{4}{|l|}{ Basal-like/claudin-low } \\
\hline MDA-MB157 & $97.4 \%[46]^{\mathrm{c}}$ & $14.0 \pm 1.8 \%[47]$ & \\
\hline HS578T & $65 \%[48], 85 \pm 5 \%[31], 99.3 \%[49]$ & & \\
\hline MDA-MB231 & $99.9 \%[46], 85 \pm 5[31], 98.6 \%$ [49], most cells [50] & $13.0 \pm 1.4 \%[47]$ & $3.40 \pm 0.60 \%[50]$ \\
\hline MDA-MB436 & $72 \pm 5 \%[31]$ & & \\
\hline HCC1937 & $17.9 \%[49]$ & & \\
\hline BT549 & $90.3 \%[46], 16.5 \%[49]$ & & \\
\hline \multicolumn{4}{|l|}{ Luminal subtype } \\
\hline MCF-7 & $0 \%[31,46], 0.028 \%[49], 1 \%[51]$ & & \\
\hline MDA-MB453 & $0 \%[46]$ & & \\
\hline T47D & $0 \%[31,46]$ & & \\
\hline SKBR3 & $0 \%[31,46]$ & & \\
\hline
\end{tabular}

perturbagens affiliated with known molecular targets and signaling pathways, and discover potential pharmaceutical treatment based on the query signatures [32]. A CMap score from +1 to -1 is assigned based on the degree of similarity or dissimilarity between two signatures [32]. Here, we used the $\mathrm{CDH} 2 / 4 / 6 / 17$-associated signature to query the CMap. If a compound with a high CMap score (close to +1$)$, it will have a similar gene pattern to that induced by $\mathrm{CDH} 2 / 4 / 6 / 17$ and may act on a parallel pathway induced by $\mathrm{CDH} 2 / 4 / 6 / 17$; if the score is close to -1 , the perturbagen may counteract the effects induced by the alterations of these CDHs. First, we focused on the perturbagens, which are better related to known molecular targets and signaling pathways. For instance, we found that the $\mathrm{CDH} 2 / 4 / 6 / 17$-associated signature was similar to paclitaxel-induced signature (Table 5). Since paclitaxel is a microtubule-damaging agent and functions partially through p70S6K activation via multiple signaling pathways including ERK1/2 MAPK, JNK, PKC, $\mathrm{Ca}^{++}$, PI3K/mTOR [52], it provided evidence to support the finding revealed by analysis of GO/KEGG, as described above (Figure 2(b)). Next, we investigated whether some compounds can be used to target the cases with the $\mathrm{CDH} 2 / 4 / 6 / 17$-associated signatures. As shown in Table 6, multiple drugs were identified that had a significantly anticorrelating gene pattern to that induced by $\mathrm{CDH} 2 / 4 / 6 / 17$. For instance, resveratrol and its derivatives had been reported to exhibit anticancer activity in TNBC cells possibly through interfering with epigenetic regulation $[53,54]$. Thus, our findings provided additional evidence to support the claim that the affected pathways were induced by $\mathrm{CDH} 2 / 4 / 6 / 17$ and revealed that the perturbagens predicted here might be used to target TNBC with the alterations of CDH2/4/6/17-SC-TFs axis.

\section{Discussion}

In this study, we evaluated the status of CDHs in TCGA breast cancer samples, especially in TNBC by using informatics and experimental analyses, and demonstrated that $\mathrm{CDH} 2 / 4 / 6 / 17$ themselves and their associated SC-TFs including WWTR1, NFYA, and FOXM1 might be involved in the enrichment of CSCs in TNBC.

$\mathrm{CDH} 1$ is an original cadherin and plays a pivotal role in epithelial structure remodeling and maintaining the stemness of stem cells in breast epithelial and cancer cells [5-7, 38-40]. 
TABLE 5: Top 10 perturbagens identified through the Connectivity Map that induce the CDH-associated signature.

\begin{tabular}{|c|c|c|c|c|c|}
\hline $\begin{array}{l}\text { Pharmaceutical } \\
\text { perturbagen }\end{array}$ & $\begin{array}{l}\text { Enrichment } \\
\text { CMap score }\end{array}$ & $\operatorname{Rank}^{\mathrm{a}}$ & $n^{\mathrm{b}}$ & $p$ value & Description \\
\hline Trimethobenzamide & 0.885 & 5 & 5 & 0.00006 & $\begin{array}{c}\text { An antiemetic used to } \\
\text { prevent nausea and } \\
\text { vomiting }\end{array}$ \\
\hline Felbinac & 0.892 & 7 & 4 & 0.00012 & $\begin{array}{c}\text { A nonsteroidal } \\
\text { anti-inflammatory drug of } \\
\text { the arylacetic acid class }\end{array}$ \\
\hline Iopamidol & 0.886 & 8 & 4 & 0.00018 & $\begin{array}{l}\text { A radiopaque contrast } \\
\text { agent }\end{array}$ \\
\hline Diethylstilbestrol & 0.738 & 13 & 6 & 0.00085 & $\begin{array}{l}\text { A synthetic, nonsteroidal } \\
\text { estrogen, and a potent } \\
\text { agonist of estrogen } \\
\text { receptors }\end{array}$ \\
\hline Adiphenine & 0.789 & 14 & 5 & 0.00092 & $\begin{array}{l}\text { An inhibitor of nicotinic } \\
\text { receptors }\end{array}$ \\
\hline Paclitaxel & 0.728 & 17 & 6 & 0.00107 & $\begin{array}{l}\text { A microtubule-damaging } \\
\text { agent, affecting mitosis }\end{array}$ \\
\hline Thioperamide & 0.754 & 20 & 5 & 0.00216 & $\begin{array}{c}\text { A potent antagonist of } \\
\text { histamine receptor } \mathrm{H} 3 / \mathrm{H} 4\end{array}$ \\
\hline Cinchonine & 0.813 & 21 & 4 & 0.00237 & $\begin{array}{c}\text { A multidrug } \\
\text { resistance-reversing agent }\end{array}$ \\
\hline Diphenhydramine & 0.737 & 25 & 5 & 0.00290 & An antihistamine agent \\
\hline Vinburnine & 0.796 & 28 & 4 & 0.00334 & $\begin{array}{c}\text { A vinca alkaloid acting as a } \\
\text { vasodilator }\end{array}$ \\
\hline
\end{tabular}

Note. ${ }^{a}$ Rank by $p$ value. ${ }^{b} n$ indicates the number of instances related to this perturbagen tested in the Connectivity Map.

TABLE 6: Top 10 perturbagens identified through the Connectivity Map that anticorrelated with the CDH-associated signature.

\begin{tabular}{|c|c|c|c|c|c|}
\hline $\begin{array}{l}\text { Pharmaceutical } \\
\text { perturbagen }\end{array}$ & $\begin{array}{l}\text { Enrichment CMap } \\
\text { score }\end{array}$ & $\operatorname{Rank}^{\mathrm{a}}$ & $n^{\mathrm{b}}$ & $p$ value & Description $^{c}$ \\
\hline Resveratrol & -0.765 & 1 & 9 & $<0.00001$ & $\begin{array}{l}\text { A stilbenoid, a type of natural } \\
\text { phenol }\end{array}$ \\
\hline Trifluoperazine & -0.553 & 2 & 16 & $<0.00001$ & $\begin{array}{l}\text { A blocker of dopamine D1/D2 } \\
\text { receptor }\end{array}$ \\
\hline 0297417-0002B & -0.981 & 3 & 3 & 0.00004 & N.D. \\
\hline MG-262 & -0.939 & 9 & 3 & 0.00032 & A proteasome inhibitor \\
\hline Apigenin & -0.866 & 10 & 4 & 0.00062 & $\begin{array}{c}\text { A potent inhibitor of CYP2C9; a } \\
\text { monoamine transporter activator; a } \\
\text { ligand for central benzodiazepine } \\
\text { receptors }\end{array}$ \\
\hline Pyrvinium & -0.740 & 11 & 6 & 0.00066 & An antinematodal agent \\
\hline Methotrexate & -0.654 & 12 & 8 & 0.00078 & $\begin{array}{l}\text { An inhibitor of dihydrofolate } \\
\text { reductase (DHFR), participating in } \\
\text { DNA repair; a suppressant of } \\
\text { immunology }\end{array}$ \\
\hline Amiodarone & -0.777 & 15 & 5 & 0.00096 & A calcium channel blocker \\
\hline Piperidolate & -0.908 & 19 & 3 & 0.00142 & An antimuscarinic \\
\hline Acepromazine & -0.811 & 24 & 4 & 0.00251 & $\begin{array}{l}\text { A phenothiazine derivative } \\
\text { antipsychotic drug }\end{array}$ \\
\hline
\end{tabular}

Note. ${ }^{a}$ Rank by $p$ value. ${ }^{b} n$ indicates the number of instances related to these perturbagens tested in the Connectivity Map. ${ }^{c}$ N.D., not determined.

However, CDH1 was low expressed in TNBC (Figure 1) $[36,37]$, and $\mathrm{CDH} 1$ alteration events were mutually exclusive with high-level alterations (amplification or upregulation) of most of SC-TFs used in this study in breast cancers
(Supplementary Table S2). As such, CDH1 may be not a key protein in the enrichment of CSCs in TNBC. Therefore, it raised a challenging question as to whether other $\mathrm{CDH}$ s have an effect on CSCs when CDH1 is low expressed or mutated 
in TNBC. Here, we shed lights on the CDHs and provided insights into the potential roles of $\mathrm{CDH} 2,4,6,17$ in CSCs of TNBC. We clearly demonstrated that $\mathrm{CDH} 2 / 4 / 6 / 17$ alterations including amplifications and upregulation happened at a higher frequency (47\%) in TNBC samples (Figure 1), which was correlated with the elevated expression of SCTFs (Table 1), and also the enrichment of CSCs in TNBC (Figure 3 and Table 4), indicating CDH2/4/6/17 might have a potential role in the accumulation of CSCs in TNBC. As previously reported, $\mathrm{CDH} 2$ was often upregulated in cancers including breast cancers and acts as a promoting factor of cancer invasion and metastasis $[10,55,56]$. Moreover, CDH2 can regulate an EMT-like behavior [10], which is one of the properties belonging to the CSCs, and can even directly regulate stem cell fate decision $[11,12]$. As for $\mathrm{CDH} 4, \mathrm{CDH} 6$, and $\mathrm{CDH} 17$, although there was rare emerging evidence to demonstrate their possible direct roles in the CSCs, a few reports demonstrated their functional roles in epithelial structure and even in regulation of EMT-like activity [57-60]. These studies are in consistency with our results and therefore support our notion here that $\mathrm{CDH} 2,4,6$, and 17 may have an implication in the CSCs in TNBC.

Our study here demonstrated that SC-TFs such as WWTR1, FOXM1, NFYA, and SOX9 might be involved in the enrichment of CSCs in TNBC (Figure 3, Tables 1 and 4). Consistently, these SC-TFs have been identified to be involved in stem cell regulation [22, 61-66]. For example, WWTR1 (also called TAZ), together with Yes-associated protein (YAP), is a key transcription regulator in Hippo-YAP signaling pathway, which is crucial for self-renewal of stem cells [28, 66-69]. Recently, several studies demonstrated that WWTR1/TAZ was strongly associated with triple-negative phenotype, and can sustain self-renewal potential of breast CSCs and increase the population of CSCs in TNBC [70-73]. When we prepared this manuscript, a report demonstrated that $\mathrm{CDH} 2$ indeed modulates mesenchymal cancer stem cells through WWTR1/TAZ [74], supporting our result of WWTR1's potential role in the enrichment of CSCs in TNBC induced by $\mathrm{CDH} 2$ in combination with $\mathrm{CDH} 4,6$, and 17. Another important SC-TF is FOXM1. Likely, FOXM1 has also been reported to be involved in the EMT remodeling, self-renewal and the maintenance of stemness of stem cells [64, 75-77]. FOXM1 was highly upregulated in TNBC [78], confirming its role in the accumulation of CSCs in TNBC. Therefore, together with our results that $\mathrm{CDH} 2 / 4 / 6 / 17$ alterations were accompanied with elevated expression of SCTFs (Tables 1 and 2), and TNBC are enriched in stem cell population (Figure 3, Table 4) [4, 79], this may provide a novel insight into the enrichment of CSCs in TNBC. In other words, $\mathrm{CDH} 2 / 4 / 6 / 17$ overexpressed individually or in combination might strengthen the inappropriate signals outside in, which may in turn trigger $\mathrm{CDH} 2 / 4 / 6 / 17$-related signal pathways to enhance the activity of SC-TFs such as WWTR1 and FOXM1, etc. The latter may then maintain the stem cell properties and increase the reservoir of CSCs in TNBC. Although this signal cascade remains to be investigated, our data provide a meaningful clue to further understand the mechanism underlying the maintenance of CSC in TNBC where CDH1 is often lost or mutated.
Although CDH1 is key for the maintenance of epithelial stem cells $[5,7,80]$, many reports reveal that CDH1 loss is associated with EMT [81, 82], a cancer stem cell-like behavior [39], and its deficiency is characteristic of invasive breast lobular carcinomas, especially in TNBC $[36,37]$. Our study showed that the level of CDH1 had a positive correlation with the status of ESR1 and HER2 (Supplementary Table S1), and CDH1 was low expressed/mutated in TNBC (Figure 1). Together with our notion that $\mathrm{CDH} 2 / 4 / 6 / 17$ contributed to the enrichment of CSCs in TNBC, it raised a question that which part (CDH1 low or $\mathrm{CDH} 2 / 4 / 6 / 17$ high or in combination) was more important for the enrichment of CSCs in TNBC. Frankly speaking, it is still an open issue. However, our results here supported the hypothesis that the elevated level of $\mathrm{CDH} 2 / 4 / 6 / 17$ may have a prevailing effect on the accumulation of CSCs than the decreased level of $\mathrm{CDH} 1$ in TNBC. The high level of $\mathrm{CDH}$-associated SC-TFs such as FOXM1, MCM2, SOX9, and SNAI1 were concurrent with the overexpression of $\mathrm{CDH} 2,4,6$, and 17 (Table 1), but mutually exclusive with the decrease of CDH1 (Supplementary Table S2), strongly suggested that the enrichment of CSCs was more closely related to the high of $\mathrm{CDH} 2,4,6$, and 17, but not to the low of CDH1. Consistently, $\mathrm{CDH} 2$ has been identified as an indicator of EMT, and strongly correlated with CD133, one of the stem cell markers $[11,12,83]$. Moreover, CDH2 has a role in cell migration and metastasis over $\mathrm{CDH} 1$. For instance, $\mathrm{CDH} 2$ promotes cell motility in breast cancer cells regardless of the expression of CDH1 [84]. Also, CDH2 positivity in IHC staining was correlated to lymph node metastasis of TNBC, but CDH1 was not [85]. Altogether, our data support the hypothesis here that $\mathrm{CDH} 2 / 4 / 6 / 17$ may have a direct effect on the enrichment of CSCs in TNBC, which may have an implication in targeted therapy for TNBC in the future.

\section{Conclusion}

In this study, we demonstrated that $\mathrm{CDH} 2 / 4 / 6 / 17$ were amplified/overexpressed in TNBC, where the expression of $\mathrm{CDH} 2 / 4 / 6 / 17$-enriched SC-TFs was also increased. In parallel, these SC-TFs were strongly associated with the accumulation of CSCs in TNBC cells. Thus, we concluded that one mechanism through which the stemness is maintained in TNBC when E-cadherin is downregulated or lost is by way of upregulating the expression of other $\mathrm{CDH}$ family members such as $\mathrm{CDH} 2 / 4 / 6 / 17$ along with increased expression of SC-TFs. Moreover, we demonstrated that small compounds might be used to target TNBC based on alterations of $\mathrm{CDH} 2 / 4 / 6 / 17$ and SC-TFs. Although further studies have to be conducted on the mechanisms for regulation of SCTFs by $\mathrm{CDH} 2 / 4 / 6 / 17$, all these observations highlight the potential functions of $\mathrm{CDH} 2 / 4 / 6 / 17$ on the reservoir of CSCs in TNBC with low expression or mutation of CDH1 and provide evidence with implications in targeted therapy in TNBC.

\section{Competing Interests}

The authors declare no financial conflict of interests. 


\section{Acknowledgments}

This work was supported by a grant of National Natural Science Foundation of China (NSFC) to Yulong Liang (81372589) and partly by a NSFC Grant (31301143).

\section{References}

[1] R. T. Lawrence, E. M. Perez, D. Hernández et al., "The proteomic landscape of triple-negative breast cancer," Cell Reports, vol. 11, no. 4, pp. 630-644, 2015.

[2] C. M. Perou, T. Sørile, M. B. Eisen et al., "Molecular portraits of human breast tumours," Nature, vol. 406, no. 6797, pp. 747-752, 2000.

[3] C. M. Perou, "Molecular stratification of triple-negative breast cancers," The Oncologist, vol. 15, pp. 39-48, 2010.

[4] A. Prat and C. M. Perou, "Deconstructing the molecular portraits of breast cancer," Molecular Oncology, vol. 5, no. 1, pp. 5-23, 2011.

[5] L. Li, S. A. L. Bennett, and L. Wang, "Role of E-cadherin and other cell adhesion molecules in survival and differentiation of human pluripotent stem cells," Cell Adhesion and Migration, vol. 6, no. 1, pp. 59-70, 2012.

[6] F. Soncin and C. M. Ward, "The function of E-cadherin in stem cell pluripotency and self-renewal," Genes, vol. 2, no. 1, pp. 229259, 2011.

[7] T. Pieters and F. van Roy, "Role of cell-cell adhesion complexes in embryonic stem cell biology," Journal of Cell Science, vol. 127, no. 12, pp. 2603-2613, 2014.

[8] T. Redmer, S. Diecke, T. Grigoryan, A. Quiroga-Negreira, W. Birchmeier, and D. Besser, "E-cadherin is crucial for embryonic stem cell pluripotency and can replace OCT4 during somatic cell reprogramming," EMBO Reports, vol. 12, no. 7, pp. 720-726, 2011.

[9] M. I. García-Castro, E. Vielmetter, and M. Bronner-Fraser, "Ncadherin, a cell adhesion molecule involved in establishment of embryonic left-right asymmetry," Science, vol. 288, no. 5468, pp. 1047-1051, 2000.

[10] G. Agiostratidou, J. Hulit, G. R. Phillips, and R. B. Hazan, "Differential cadherin expression: potential markers for epithelial to mesenchymal transformation during tumor progression," Journal of Mammary Gland Biology and Neoplasia, vol. 12, no. 23, pp. 127-133, 2007.

[11] T. Takehara, T. Teramura, Y. Onodera, J. Frampton, and K. Fukuda, "Cdh2 stabilizes FGFR1 and contributes to primedstate pluripotency in mouse epiblast stem cells," Scientific Reports, vol. 5, article 14722, 2015.

[12] S. Alimperti and S. T. Andreadis, "CDH2 and CDH11 act as regulators of stem cell fate decisions," Stem Cell Research, vol. 14, no. 3, pp. 270-282, 2015.

[13] E. Cerami, J. Gao, U. Dogrusoz et al., "The cBio Cancer Genomics Portal: an open platform for exploring multidimensional cancer genomics data," Cancer Discovery, vol. 2, no. 5, pp. 401-404, 2012.

[14] H. Zhao, A. Langerød, Y. Ji et al., "Different gene expression patterns in invasive lobular and ductal carcinomas of the breast," Molecular Biology of the Cell, vol. 15, no. 6, pp. 2523-2536, 2004.

[15] C. Curtis, S. P. Shah, S.-F. Chin et al., "The genomic and transcriptomic architecture of 2,000 breast tumours reveals novel subgroups," Nature, vol. 486, no. 7403, pp. 346-352, 2012.
[16] J. Barretina, G. Caponigro, N. Stransky et al., “The Cancer Cell Line Encyclopedia enables predictive modelling of anticancer drug sensitivity," Nature, vol. 483, no. 7391, pp. 603-607, 2012.

[17] L. M. Heiser, A. Sadanandam, W. L. Kuo et al., "Subtype and pathway specific responses to anticancer compounds in breast cancer," Proceedings of the National Academy of Sciences of the United States of America, vol. 109, pp. 2724-2729, 2012.

[18] K. Takahashi and S. Yamanaka, "A decade of transcription factor-mediated reprogramming to pluripotency," Nature Reviews Molecular Cell Biology, vol. 17, no. 3, pp. 183-193, 2016.

[19] S. Palomäki, M. Pietilä, S. Laitinen et al., "HIF-1 $\alpha$ is upregulated in human mesenchymal stem cells," Stem Cells, vol. 31, no. 9, pp. 1902-1909, 2013.

[20] S. R. Martins-Neves, W. E. Corver, D. I. Paiva-Oliveira et al., "Osteosarcoma stem cells have active Wnt/ $\beta$-catenin and overexpress SOX2 and KLF4," Journal of Cellular Physiology, vol. 231, no. 4, pp. 876-886, 2016.

[21] P.-M. Chen, C.-H. Lin, N.-T. Li et al., "C-Maf regulates pluripotency genes, proliferation/self-renewal, and lineage commitment in ROS-mediated senescence of human mesenchymal stem cells," Oncotarget, vol. 6, no. 34, pp. 35404-35418, 2015.

[22] S. C. Pruitt, K. J. Bailey, and A. Freeland, "Reduced Mcm2 expression results in severe stem/progenitor cell deficiency and cancer," Stem Cells, vol. 25, no. 12, pp. 3121-3132, 2007.

[23] S.-H. Kim, M. O. Kim, Y.-Y. Cho et al., "ERK1 phosphorylates Nanog to regulate protein stability and stem cell self-renewal," Stem Cell Research, vol. 13, no. 1, pp. 1-11, 2014.

[24] U. Wellner, J. Schubert, U. C. Burk et al., "The EMT-activator ZEB1 promotes tumorigenicity by repressing stemnessinhibiting microRNAs," Nature Cell Biology, vol. 11, no. 12, pp. 1487-1495, 2009.

[25] M. Abu-Remaileh, A. Gerson, M. Farago et al., "Oct-3/4 regulates stem cell identity and cell fate decisions by modulating Wnt/ $\beta$-catenin signalling," The EMBO Journal, vol. 29, no. 19, pp. 3236-3248, 2010.

[26] Y. Hou, W. Li, Y. Sheng et al., "The transcription factor Foxml is essential for the quiescence and maintenance of hematopoietic stem cells," Nature Immunology, vol. 16, no. 8, pp. 810-818, 2015.

[27] Y. Lin, X.-Y. Li, A. L. Willis, C. Liu, G. Chen, and S. J. Weiss, "Snaill-dependent control of embryonic stem cell pluripotency and lineage commitment," Nature Communications, vol. 5, article 3070, 2014.

[28] T. Panciera, L. Azzolin, A. Fujimura et al., "Induction of expandable tissue-specific stem/progenitor cells through transient expression of YAP/TAZ," Cell Stem Cell, vol. 19, no. 6, pp. 725-737, 2016.

[29] L. Lu, D. Katsaros, K. Shaverdashvili et al., "Pluripotent factor lin-28 and its homologue lin-28b in epithelial ovarian cancer and their associations with disease outcomes and expression of let-7a and IGF-II," European Journal of Cancer, vol. 45, no. 12, pp. 2212-2218, 2009.

[30] M. Kanatsu-Shinohara, T. Tanaka, N. Ogonuki et al., "Myc/ Mycn-mediated glycolysis enhances mouse spermatogonial stem cell self-renewal," Genes \& Development, vol. 30, no. 23, pp. 2637-2648, 2016.

[31] C. Sheridan, H. Kishimoto, R. K. Fuchs et al., "CD44 $4^{+} / \mathrm{CD} 24^{-}$ breast cancer cells exhibit enhanced invasive properties: an early step necessary for metastasis," Breast Cancer Research, vol. 8, article R59, 2006.

[32] J. Lamb, E. D. Crawford, D. Peck et al., "The connectivity map: using gene-expression signatures to connect small molecules, 
genes, and disease," Science, vol. 313, no. 5795, pp. 1929-1935, 2006.

[33] J. M. Rosenbluth, D. J. Mays, M. F. Pino, J. T. Luo, and J. A. Pietenpol, "A gene signature-based approach identifies mTOR as a regulator of p73," Molecular and Cellular Biology, vol. 28, no. 19, pp. 5951-5964, 2008.

[34] G. Turashvili, J. Bouchal, K. Baumforth et al., "Novel markers for differentiation of lobular and ductal invasive breast carcinomas by laser microdissection and microarray analysis," BMC Cancer, vol. 7, article no. 55, 2007.

[35] G. Ciriello, M. L. Gatza, A. H. Beck et al., "Comprehensive molecular portraits of invasive lobular breast cancer," Cell, vol. 163, no. 2, pp. 506-519, 2015.

[36] B. Mahler-Araujo, K. Savage, S. Parry, and J. S. Reis-Filho, "Reduction of E-cadherin expression is associated with nonlobular breast carcinomas of basal-like and triple negative phenotype," Journal of Clinical Pathology, vol. 61, no. 5, pp. 615620, 2008.

[37] M. A. Aleskandarany, O. H. Negm, A. R. Green et al., "Epithelial mesenchymal transition in early invasive breast cancer: an immunohistochemical and reverse phase protein array study," Breast Cancer Research and Treatment, vol. 145, no. 2, pp. 339348, 2014.

[38] G. Dontu and M. S. Wicha, "Survival of mammary stem cells in suspension culture: implications for stem cell biology and neoplasia," Journal of Mammary Gland Biology and Neoplasia, vol. 10, no. 1, pp. 75-86, 2005.

[39] S. A. Mani, W. Guo, M.-J. Liao et al., "The epithelial-mesenchymal transition generates cells with properties of stem cells," Cell, vol. 133, no. 4, pp. 704-715, 2008.

[40] P. Mallini, T. Lennard, J. Kirby, and A. Meeson, "Epithelial-tomesenchymal transition: what is the impact on breast cancer stem cells and drug resistance," Cancer Treatment Reviews, vol. 40, no. 3, pp. 341-348, 2014.

[41] Y. Zhang, S. Stehling-Sun, K. Lezon-Geyda et al., "PR-domaincontaining Mdsl-Evil is critical for long-term hematopoietic stem cell function," Blood, vol. 118, no. 14, pp. 3853-3861, 2011.

[42] S. Mamat, J.-I. Ikeda, T. Tian et al., “Transcriptional regulation of aldehyde dehydrogenase 1A1 gene by alternative spliced forms of nuclear factor $\mathrm{Y}$ in tumorigenic population of endometrial adenocarcinoma," Genes and Cancer, vol. 2, no. 10, pp. 979984, 2011.

[43] S. Hiraguri, T. Godfrey, H. Nakamura et al., "Mechanisms of inactivation of E-cadherin in breast cancer cell lines," Cancer Research, vol. 58, no. 9, pp. 1972-1977, 1998.

[44] Y. L. Chao, C. R. Shepard, and A. Wells, "Breast carcinoma cells re-express E-cadherin during mesenchymal to epithelial reverting transition," Molecular Cancer, vol. 9, article 179, 2010.

[45] W. Lehmann, D. Mossmann, J. Kleemann et al., “ZEB1 turns into a transcriptional activator by interacting with YAP1 in aggressive cancer types," Nature Communications, vol. 7, Article ID 10498, 2016.

[46] W. Liu, G. Jeganathan, S. Amiri, K. M. Morgan, B. M. Ryan, and S. R. Pine, "Asymmetric segregation of template DNA strands in basal-like human breast cancer cell lines," Molecular Cancer, vol. 12, no. 1, article no. 139, 2013.

[47] J. Kurebayashi, N. Kanomata, T. Moriya, Y. Kozuka, M. Watanabe, and H. Sonoo, "Preferential antitumor effect of the Src inhibitor dasatinib associated with a decreased proportion of aldehyde dehydrogenase 1-positive cells in breast cancer cells of the basal B subtype," BMC Cancer, vol. 10, article 568, 2010.
[48] L. Hughes, C. Malone, S. Chumsri, A. M. Burger, and S. McDonnell, "Characterisation of breast cancer cell lines and establishment of a novel isogenic subclone to study migration, invasion and tumourigenicity," Clinical and Experimental Metastasis, vol. 25, no. 5, pp. 549-557, 2008.

[49] Y. Arima, N. Hayashi, H. Hayashi et al., "Loss of p16 expression is associated with the stem cell characteristics of surface markers and therapeutic resistance in estrogen receptor-negative breast cancer," International Journal of Cancer, vol. 130, no. 11, pp. 2568-2579, 2012.

[50] T. Hiraga, S. Ito, and H. Nakamura, "Side population in MDAMB-231 human breast cancer cells exhibits cancer stem cell-like properties without higher bone-metastatic potential," Oncology Reports, vol. 25, no. 1, pp. 289-296, 2011.

[51] G. B. Sajithlal, K. Rothermund, F. Zhang et al., "Permanently blocked stem cells derived from breast cancer cell lines," Stem Cells (Dayton, Ohio), vol. 28, no. 6, pp. 1008-1018, 2010.

[52] X.-F. Le, W. N. Hittelman, J. Liu et al., "Paclitaxel induces inactivation of p70 S6 kinase and phosphorylation of Thr421 and Ser424 via multiple signaling pathways in mitosis," Oncogene, vol. 22, no. 4, pp. 484-497, 2003.

[53] R. Kala, H. N. Shah, S. L. Martin, and T. O. Tollefsbol, "Epigenetic-based combinatorial resveratrol and pterostilbene alters DNA damage response by affecting SIRT1 and DNMT enzyme expression, including SIRT1-dependent $\gamma$-H2AX and telomerase regulation in triple-negative breast cancer," $B M C$ Cancer, vol. 15, article 672, 2015.

[54] R. Medina-Aguilar, C. Pérez-Plasencia, L. A. Marchat et al., "Methylation landscape of human breast cancer cells in response to dietary compound resveratrol," PLOS ONE, vol. 11, no. 6, Article ID e0157866, 2016.

[55] R. B. Hazan, G. R. Phillips, R. F. Qiao, L. Norton, and S. A. Aaronson, "Exogenous expression of $\mathrm{N}$-cadherin in breast cancer cells induces cell migration, invasion, and metastasis," Journal of Cell Biology, vol. 148, no. 4, pp. 779-790, 2000.

[56] R. B. Hazan, R. Qiao, R. Keren, I. Badano, and K. Suyama, "Cadherin switch in tumor progression," Annals of the New York Academy of Sciences, vol. 1014, pp. 155-163, 2004.

[57] G. Agiostratidou, M. Li, K. Suyama et al., "Loss of retinal cadherin facilitates mammary tumor progression and metastasis," Cancer Research, vol. 69, no. 12, pp. 5030-5038, 2009.

[58] C. Du, T. Huang, D. Sun et al., "CDH4 as a novel putative tumor suppressor gene epigenetically silenced by promoter hypermethylation in nasopharyngeal carcinoma," Cancer Letters, vol. 309, no. 1, pp. 54-61, 2011.

[59] W. Baumgartner, "Possible roles of LI-Cadherin in the formation and maintenance of the intestinal epithelial barrier," Tissue Barriers, vol. 1, no. 1, Article ID e23815, 2013.

[60] M. R. Clay and M. C. Halloran, "Cadherin 6 promotes neural crest cell detachment via F-actin regulation and influences active Rho distribution during epithelial-to-mesenchymal transition," Development, vol. 141, no. 12, pp. 2506-2515, 2014.

[61] J. Zhu, Y. Zhang, G. J. Joe, R. Pompetti, and S. G. Emerson, "NFYa activates multiple hematopoietic stem cell (HSC) regulatory genes and promotes HSC self-renewal," Proceedings of the National Academy of Sciences of the United States of America, vol. 102, no. 33, pp. 11728-11733, 2005.

[62] S. Arai, A. Yoshimi, M. Shimabe et al., "Evi-1 is a transcriptional target of mixed-lineage leukemia oncoproteins in hematopoietic stem cells," Blood, vol. 117, no. 23, pp. 6304-6314, 2011. 
[63] W. Guo, Z. Keckesova, J. L. Donaher et al., "Slug and Sox9 cooperatively determine the mammary stem cell state," Cell, vol. 148, no. 5, pp. 1015-1028, 2012.

[64] A. Gong and S. Huang, "FoxM1 and Wnt/ $\beta$-catenin signaling in glioma stem cells," Cancer Research, vol. 72, no. 22, pp. 5658$5662,2012$.

[65] K. Horvay, T. Jardé, F. Casagranda et al., "Snail regulates cell lineage allocation and stem cell maintenance in the mouse intestinal epithelium," The EMBO Journal, vol. 34, no. 10, pp. 1319-1335, 2015.

[66] A. Elbediwy, Z. I. Vincent-Mistiaen, and B. J. Thompson, "YAP and TAZ in epithelial stem cells: a sensor for cell polarity, mechanical forces and tissue damage," BioEssays, vol. 38, no. 7, pp. 644-653, 2016.

[67] L. Azzolin, F. Zanconato, S. Bresolin et al., "Role of TAZ as mediator of wnt signaling," Cell, vol. 151, no. 7, pp. 1443-1456, 2012.

[68] Y.-W. Li, H. Shen, C. Frangou et al., "Characterization of TAZ domains important for the induction of breast cancer stem cell properties and tumorigenesis," Cell Cycle, vol. 14, no. 1, pp. 146156, 2015.

[69] M. Maugeri-Saccà and R. De Maria, "Hippo pathway and breast cancer stem cells," Critical Reviews in Oncology/Hematology, vol. 99, pp. 115-122, 2016.

[70] M. Cordenonsi, F. Zanconato, L. Azzolin et al., "The hippo transducer TAZ confers cancer stem cell-related traits on breast cancer cells," Cell, vol. 147, no. 4, pp. 759-772, 2011.

[71] C. Frangou, Y.-W. Li, H. Shen et al., "Molecular profiling and computational network analysis of TAZ-mediated mammary tumorigenesis identifies actionable therapeutic targets," Oncotarget, vol. 5, no. 23, pp. 12166-12176, 2014.

[72] J. Díaz-Martín, M. Á. López-García, L. Romero-Pérez et al., "Nuclear TAZ expression associates with the triple-negative phenotype in breast cancer," Endocrine-Related Cancer, vol. 22, no. 3, pp. 443-454, 2015.

[73] M. Bartucci, R. Dattilo, C. Moriconi et al., "TAZ is required for metastatic activity and chemoresistance of breast cancer stem cells," Oncogene, vol. 34, no. 6, pp. 681-690, 2015.

[74] B. D. Cosgrove, K. L. Mui, T. P. Driscoll et al., "N-cadherin adhesive interactions modulate matrix mechanosensing and fate commitment of mesenchymal stem cells," Nature Materials, 2016.

[75] B. Bao, Z. Wang, S. Ali et al., "Over-expression of FoxM1 leads to epithelial-mesenchymal transition and cancer stem cell phenotype in pancreatic cancer cells," Journal of Cellular Biochemistry, vol. 112, no. 9, pp. 2296-2306, 2011.

[76] W.-T. Chiu, Y.-F. Huang, H.-Y. Tsai et al., "FOXM1 confers to epithelial-mesenchymal transition, stemness and chemoresistance in epithelial ovarian carcinoma cells," Oncotarget, vol. 6, no. 4, pp. 2349-2365, 2015.

[77] F. C. Kelleher and H. O'Sullivan, "FOXM1 in sarcoma: role in cell cycle, pluripotency genes and stem cell pathways," Oncotarget, vol. 7, no. 27, pp. 42792-42804, 2016.

[78] Z. Hamurcu, A. Ashour, N. Kahraman, and B. Ozpolat, "FOXM1 regulates expression of eukaryotic elongation factor 2 kinase and promotes proliferation, invasion and tumorgenesis of human triple negative breast cancer cells," Oncotarget, vol. 7, no. 13, pp. 16619-16635, 2016.

[79] G. Honeth, P.-O. Bendahl, M. Ringnér et al., "The CD $44^{+}$/ CD24- phenotype is enriched in basal-like breast tumors," Breast Cancer Research, vol. 10, article R53, 2008.
[80] T. Chen, D. Yuan, B. Wei et al., "E-cadherin-mediated cell-cell contact is critical for induced pluripotent stem cell generation," STEM CELLS, vol. 28, no. 8, pp. 1315-1325, 2010.

[81] U. Tepass, K. Truong, D. Godt, M. Ikura, and M. Peifer, "Cadherins in embryonic and neural morphogenesis," Nature Reviews Molecular Cell Biology, vol. 1, no. 2, pp. 91-100, 2000.

[82] J. Yang and R. A. Weinberg, "Epithelial-mesenchymal transition: at the crossroads of development and tumor metastasis," Developmental Cell, vol. 14, no. 6, pp. 818-829, 2008.

[83] C. Bock, C. Kuhn, N. Ditsch et al., "Strong correlation between $\mathrm{N}$-cadherin and CD133 in breast cancer: role of both markers in metastatic events," Journal of Cancer Research and Clinical Oncology, vol. 140, no. 11, pp. 1873-1881, 2014.

[84] M. T. Nieman, R. S. Prudoff, K. R. Johnson, and M. J. Wheelock, "N-cadherin promotes motility in human breast cancer cells regardless of their E-cadherin expression," Journal of Cell Biology, vol. 147, no. 3, pp. 631-643, 1999.

[85] M. Nakagawa, Y. Bando, T. Nagao et al., "Expression of p53, $\mathrm{Ki}-67, \mathrm{E}$-cadherin, N-cadherin and TOP2A in triple-negative breast cancer," Anticancer Research, vol. 31, no. 6, pp. 2389-2393, 2011. 

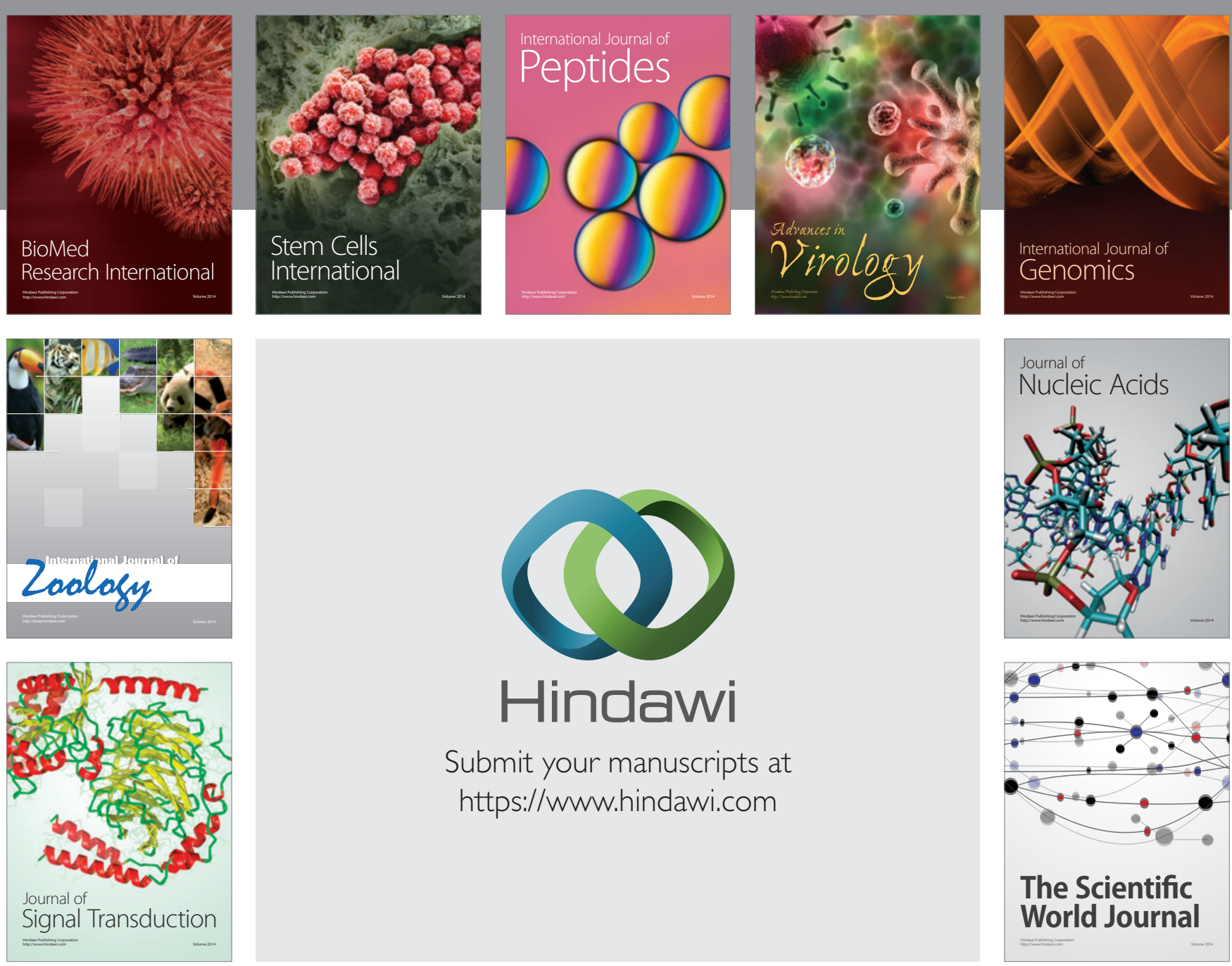

Submit your manuscripts at

https://www.hindawi.com
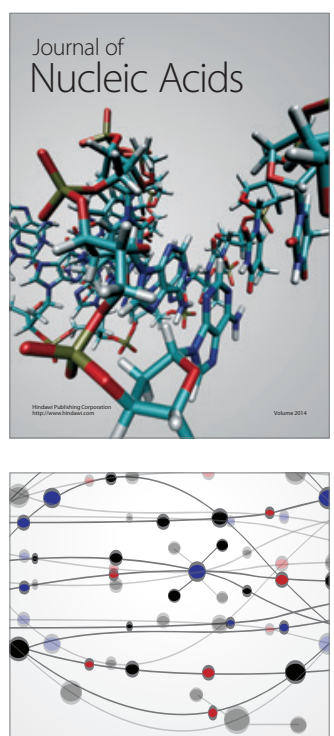

The Scientific World Journal
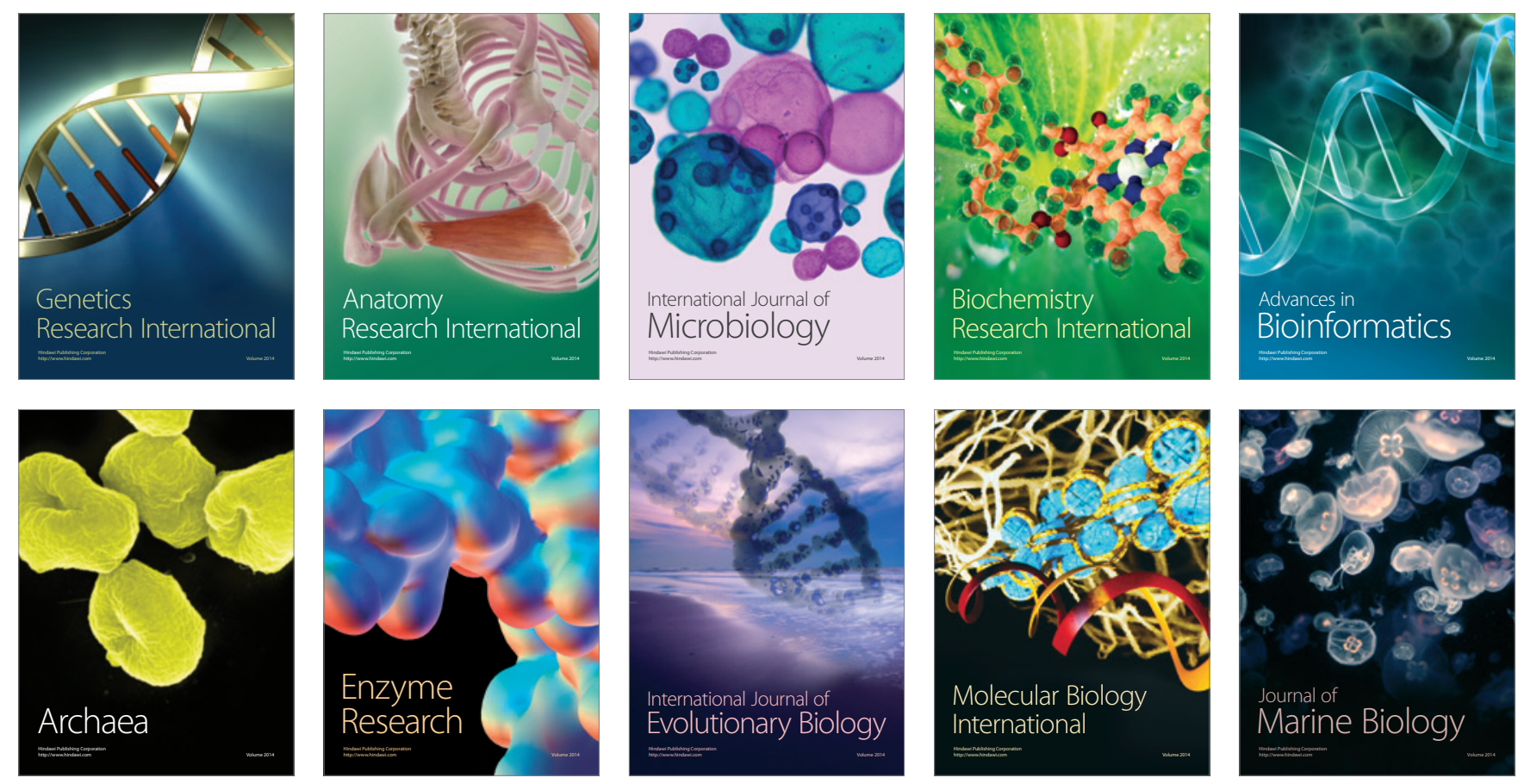